\title{
Compensation, radiographic changes, and survival in applicants for asbestosis compensation
}

\author{
W O C COOKSON, A W MUSK, J J GLANCY, N H DE KLERK, R YIN, R MELE, \\ N G CARR, B K ARMSTRONG, AND M S T HOBBS \\ From the Departments of Respiratory Medicine and Diagnostic Radiology, Sir Charles Gairdner Hospital, the \\ National Health, and Medical Research Council Research Unit in Epidemiology and Preventive Medicine, \\ and the Unit of Clinical Epidemiology, University of Western Australia, Perth, Australia
}

ABSTRACT The survival of 354 claimants for compensation for pulmonary asbestosis among former workers of the Wittenoom crocidolite mine and mill in Western Australia has been examined. There were 118 deaths up to December 1982 . The median time between start of work and claim for compensation was 17 years. The standardised mortality ratio (SMR) for deaths from all causes was 2.65 ( $p<0.0001)$. The SMR for pneumoconiosis was $177.2(p<0.0001)$, bronchitis and emphysema $2.6(p=0.04)$, tuberculosis $44.6(p<0.0001)$, respiratory cancer (including five deaths from malignant pleural mesothelioma) 6.4 ( $\mathrm{p}<0.0001$ ), gastrointestinal cancer $1.6(p=0.22)$, all other cancers $1.6(p=0.17)$, heart disease $1.4(p=0.07)$, and all other causes $2 \cdot 18(\mathrm{p}=0.004)$. Plain chest radiographs taken within two years of claiming compensation were found for 238 subjects and were categorised independently by two observers according to the International Labour Organisation criteria without knowledge of exposure or compensation details. Profusion of radiographic opacities, age at claiming compensation, work in the Wittenoom mill, and degree of disability awarded by the pneumoconiosis medical board were significant predictors of survival, but total estimated exposure to asbestos was not. Radiographic profusion and degree of disability were, however, predictable by total exposure. The median survival from claim for compensation was 17 years in subjects with ILO category 1 pneumoconiosis, 12 years in category 2 , and three years in category 3.

Increased mortality has been observed both in asbestos workers ${ }^{1-3}$ and in men with radiographic changes of pulmonary asbestosis. ${ }^{4-7}$ The causes of premature death which have been identified repeatedly are pulmonary fibrosis, carcinoma of the lung, and malignant mesothelioma of the pleura and peritoneum. An increased frequency of death from primary malignancies arising in other sites has also been reported but with less consistency. The present study examines the mortality experience and determinants of mortality in claimants for workers' compensation among former workers in the crocidolite industry at Wittenoom in Western Australia.

Crocidolite was mined and milled at Wittenoom Gorge and the nearby Colonial Gorge between

Received 2 July 1984

Accepted 13 August 1984
1943 and 1966 by a single company. Workers were exposed to crocidolite in high concentrations for relatively short periods, the average duration of employment being under four months. ${ }^{8}$ There was also exposure to silica, especially in the mine. Employment records of the company have been retained and form the basis of a continuing study ${ }^{1}$ which has shown an excess of mortality in the workforce from pneumoconiosis, respiratory cancer, malignant pleural mesothelioma, and tuberculosis. As crocidolite may be more fibrogenic than other types of asbestos ${ }^{910}$ and is more carcinogenic ${ }^{11}$ a study of the Wittenoom workers provides a unique opportunity for investigating the determinants of mortality from various causes after exposure to this type of asbestos. The present study was undertaken to extend the findings of an earlier study ${ }^{1}$ in a relatively heavily exposed subgroup with almost complete follow up. 


\section{Subjects}

Out of about 7000 workers at Wittenoom, 354 men applied for financial compensation for pneumoconiosis between 1947 and December 1982. Some did not complete the application procedure as awards were for "disability" and those still in employment were considered ineligible for compensation. They nevertheless often had asbestos related diseases and have been retained in this study. Plain chest radiographs were found for 280 of these men and had been taken within two years of an application for compensation in 241 men. Two men who died before consideration of compensation but after their radiographs had been obtained and one whose application was not considered until after December 1982 were not included in the analysis of radiographic changes. Of the remaining 238 men, 168 were awarded financial compensation for disability resulting from pneumoconiosis.

\section{Methods}

The work histories of the subjects applying for compensation were extracted from old employment records and supplemented by details from records of public hospitals in Western Australia and the Perth Chest Clinic and from questionnaires returned by former workers as part of the follow up study of all previous employees. ${ }^{1}$

Plain chest radiographs were sought from the Perth Chest Clinic, the Sir Charles Gairdner Hospital, and other public hospitals where men applying for compensation had been seen. The radiographs were classified separately by two observers according to the 1980 International Classification of Radiographs of Pneumoconiosis. ${ }^{12}$ Films were read without a knowledge of the exposure histories or details of compensation.

The duration and place of work at Wittenoom for each individual have been documented as part of a long term follow up study of the cohort.' ${ }^{1}$ The concentrations of airborne respirable fibres of crocidolite (greater than $5 \mu$ in length) in various workplaces were estimated from the results of a survey undertaken on behalf of the Mines Department of Western Australia in $1966 .{ }^{13}$ Samples for counting the number of fibres were taken with a Casella long running thermal precipitator. The duration of most samples was between four and five hours. A Casella gravimetric dust sampler and a Hexhlet were used for collecting total dust to estimate mass. Earlier measurements of dust concentrations using a konimeter had been made at Wittenoom periodically since 1948 by the Mines Department of Western Australia. The results from these surveys did not include fibre counts and had an upper limit of 1000 particles per cubic centimeter. They indicate, however, that the relative concentrations of total dust in the mill and mine have remained similar throughout the life of their operations. The 1966 results have been used to estimate earlier fibre counts, although historical information suggests that absolute fibre counts were higher for mill workers in Wittenoom Gorge before 1957, when a new mill was commissioned in Colonial Gorge. Total exposure for each individual, in fibre/cc years, was estimated from the occupational history and the 1966 fibre counts.

Altogether 118 deaths were identified by a search of all death registers in Australia from 1948 to December 1980 and the Western Australia Death Register up to December 1982 . Of the remaining 236 subjects, 189 were known to be alive after December 1982 either by direct contact via mail or telephone or by a search of the February 1983 Commonwealth electoral roll. By searching departure records of the Commonwealth Department of Immigration a further 16 subjects were found to have left Australia permanently. Seventeen of the remaining 31 subjects had been known to be alive on 31 December 1980 . The final 14 subjects were not traced beyond their initial application for compensation when all had addresses in Western Australia. As a result of these searches it is considered unlikely that any deaths occurring in Australia would have been missed.

The observed numbers of deaths were compared with the numbers expected, calculated by the manyears method ${ }^{14}$ is using age, period, and sex specific death rates for Western Australia. In computing expected numbers of deaths, subjects were followed from date of claim for compensation and those not known to be dead were censored on permanent departure from Australia or at 31 December 1982 whichever was earlier. This latter date was chosen to avoid bias in follow up resulting from subjects who have died being more easy to trace in official records. Using this date ensures no overestimation of death rates.

Causes of death were classified into the following groups according to codes of the ninth revision of $N$ the International Classification of Diseases (ICD9) (or their earlier equivalents): pneumoconiosis, $\mathcal{N}$ 5000-29, 5050-9; bronchitis and emphysema, స్ 4900-29; tuberculosis $100-189$, respiratory neo- O plasms $1600-39,2120-9,2310-9$; 2356-9, 2391; o other respiratory diseases, 4600-5199 (less $\frac{\overline{\mathbb{D}}}{2}$ pneumoconiosis, bronchitis, and emphysema); $\stackrel{\mathcal{Q}}{?}$ gastrointestinal neoplasms, 1500-99, 2110-9, ㄱ 2301-9, 2350-5, 2390; other neoplasms, 1400- 응 2399 (less respiratory and gastrointestinal neo- $\mathbb{\AA}$ plasms); heart disease, 4100-4149; and other cir- $\mathbb{D}$ 
Table 1 Standardised mortality ratios in 354 claimants for compensation for pulmonary asbestosis

\begin{tabular}{|c|c|c|c|c|}
\hline Cause of death & Observed deaths & Expected deaths & $O / E$ & $\begin{array}{l}\text { Probability } \\
\text { (one tailed test) }\end{array}$ \\
\hline $\begin{array}{l}\text { All causes } \\
\text { Pneumoconiosis } \\
\text { Bronchitis and emphysema } \\
\text { Tuberculosis } \\
\text { Other respiratory disease } \\
\text { Respiratory neoplasms* } \\
\text { Gastrointestinal cancer } \\
\text { Other cancer } \\
\text { Heart disease } \\
\text { Other circulatory diseases } \\
\text { All other }\end{array}$ & $\begin{array}{r}118 \\
28 \\
5 \\
5 \\
1 \\
26 \\
5 \\
6 \\
22 \\
4 \\
16\end{array}$ & $\begin{array}{r}44 \cdot 5 \\
0.16 \\
1 \cdot 96 \\
0 \cdot 11 \\
1 \cdot 56 \\
4 \cdot 09 \\
3 \cdot 23 \\
3.72 \\
15 \cdot 37 \\
6 \cdot 95 \\
7 \cdot 35\end{array}$ & $\begin{array}{r}2.65 \\
177 \cdot 2 \\
2 \cdot 56 \\
44 \cdot 64 \\
0.64 \\
6 \cdot 36 \\
1.55 \\
1.61 \\
1.43 \\
0.58 \\
2 \cdot 18\end{array}$ & $\begin{array}{l}0.000 \\
0.000 \\
0 \cdot 044 \\
0.000 \\
0.740 \\
0.000 \\
0.224 \\
0.173 \\
0.065 \\
0.916 \\
0.004\end{array}$ \\
\hline
\end{tabular}

*Including five cases of malignant pleural mesothelioma.

culatory disease, 3900-4599 (less heart disease).

Curves were fitted by the Kaplan-Meier method ${ }^{1617}$ for survival from the date of the radiograph closest to the date of claim for asbestosis. The effects of recorded variables on survival were examined by life table regression analysis, ${ }^{1819}$ with years of follow up from the above date as the fundamental time variable. The variables examined were age at starting work at Wittenoom, time since starting work, (log) total exposure, workplace at Wittenoom, radiographic profusion of small opacities (in major ILO categories from 0 to 3 for survival curves but in minor categories in all other analyses), and, where applicable, the percentage disability assessed by the medical panel. Information on smoking was not inchuded in the analysis because of insufficient data.

The determinants of radiographic profusion and degree of disability at the time of application for compensation were analysed by multivariate stepwise linear least squares regression analysis. ${ }^{20} 21$ The independent variables were age at starting work,

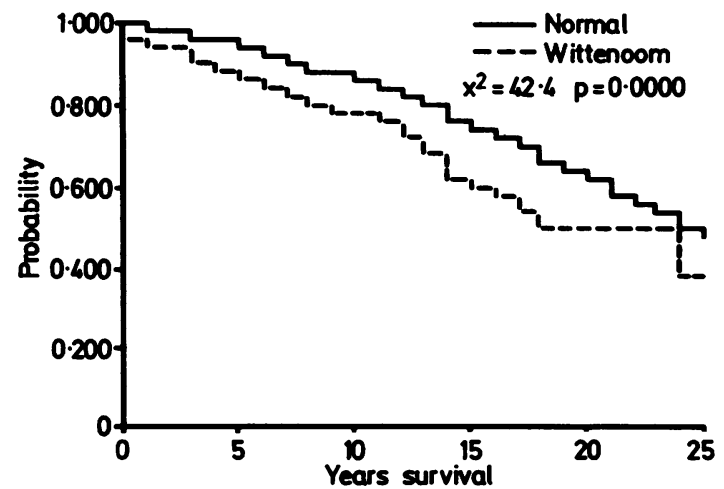

Fig 1 Survival from time of radiograph within two years of compensation for asbestos related disease in 238 subjects compared with normal population. (log) total exposure, work place at Wittenoom, and time since starting work. The determinants of degree of disability were similarly analysed with these same independent variables.

\section{Results}

There were 118 deaths in the 354 subjects studied and there was a significant excess of deaths from all causes (table 1, fig 1). Pneumoconiosis, malignant pleural mesothelioma, respiratory cancer, bronchitis and emphysema, and tuberculosis all contributed to the excess mortality.

Plain chest radiographs taken within two years of application for compensation were available for 238 subjects. Subjects in whom chest radiographs were found were younger at starting work (mean 32.3 years, standard error of mean 0.54 years) than those in whom the chest radiographs could not be found (mean 38.7 years, standard error of mean 1.19 years). Only $25 \%$ of the subjects with radiographs had died compared with $50 \%$ of the 116 subjects without $x$ ray films. The geometric mean total estimated exposure to asbestos did not differ significantly between those with radiographs and those without (56 fibres/cc years, $95 \%$ confidence interval 29-99 fibre/cc years, compared with 74 fibres/cc years, $95 \%$ confidence interval 49-113 fibre/cc years). (The estimated geometric mean total asbestos exposure of the whole population' was 7 fibres/cc years.) The pattern of mortality in the 238 subjects with radiographs did not differ significantly from the pattern observed in the other 116 subjects. By comparison with the general population the ratio of observed to expected numbers of deaths in these 238 subjects was $2 \cdot 33$. Pneumoconiosis ( 14 deaths, $\mathrm{O} / \mathrm{E} 162.9$ ) and respiratory neoplasms (14 deaths, $\mathrm{O} / \mathrm{E} \mathrm{5.72)}$ were the most common causes of death.

The relation between radiographic category and mortality was examined separately for each reader's observations of radiographic changes. There were 
Table 2 Agreement between observers in assignment of ILO classification of parenchymal asbestosis in radiographs taken within two years of claim for compensation in 238 subjects

\begin{tabular}{|c|c|c|c|c|c|c|c|c|c|c|c|c|}
\hline & & $0 / 0$ & $0 / 1$ & $\begin{array}{l}\text { Reac } \\
1 / 0\end{array}$ & $r 2: I$ & $O \underset{1 / 2}{\mathrm{grac}}$ & of $p$ & $\underset{2 / 2}{\operatorname{moco}_{2}}$ & ${ }_{2 / 3}$ & $3 / 2$ & $3 / 3$ & $3 / 4$ \\
\hline \multirow{4}{*}{ Reader 1: ILO grade of pneumoconiosis } & $\begin{array}{l}0 / 0 \\
0 / 1\end{array}$ & $\begin{array}{l}33 \\
14\end{array}$ & $\begin{array}{l}6 \\
6\end{array}$ & $\begin{array}{l}7 \\
7\end{array}$ & $\begin{array}{l}4 \\
4\end{array}$ & 2 & & & & \multirow{4}{*}{1} & & \\
\hline & $\begin{array}{l}1 / 0 \\
1 / 1 \\
1 / 2\end{array}$ & 8 & 2 & $\begin{array}{r}20 \\
5\end{array}$ & $\begin{array}{r}16 \\
15 \\
3\end{array}$ & $\begin{array}{l}7 \\
7 \\
6\end{array}$ & $\begin{array}{l}1 \\
4 \\
8\end{array}$ & $\begin{array}{l}4 \\
0\end{array}$ & 1 & & & \\
\hline & $\begin{array}{l}2 / 1 \\
2 / 2 \\
2 / 3\end{array}$ & & & & & 3 & $\begin{array}{l}8 \\
5\end{array}$ & $\begin{array}{l}3 \\
8 \\
3\end{array}$ & $\begin{array}{l}1 \\
2 \\
1\end{array}$ & & 1 & \multirow[t]{2}{*}{1} \\
\hline & $\begin{array}{l}3 / 2 \\
3 / 3 \\
3 / 4\end{array}$ & & & & & & 1 & 1 & $\begin{array}{l}2 \\
2\end{array}$ & & $\begin{array}{l}1 \\
1\end{array}$ & \\
\hline
\end{tabular}

Kendalls tau $\mathrm{B}=0.73 . \mathrm{p}<0.001$.

Table 3 Predictors of cause of death in 238 subjects with valid radiographs (proportional hazards regression analysis)

\begin{tabular}{|c|c|c|c|c|c|}
\hline & Reader & Relative risks (p) & & & \\
\hline $\begin{array}{l}\text { All causes } \\
\quad(52 \text { deaths })\end{array}$ & $\begin{array}{l}1 \\
2\end{array}$ & $\begin{array}{l}\text { Profusion* } \\
1.26(0.0001) \S \\
\text { Profusion* } \\
1.23(0.0005)\end{array}$ & $\begin{array}{l}\text { Age started work } \dagger \\
1.63(0.002) \\
\text { Age started work } \dagger \\
1.58(0.003)\end{array}$ & $\begin{array}{l}\text { Years since started work } \dagger \\
1.75(0.013) \\
\text { Years since started work } \dagger \\
1.74(0.013)\end{array}$ & $\begin{array}{c}\text { Millworking } \\
1.76(0.036) \\
\text { Millworking } \\
1.73(0.042)\end{array}$ \\
\hline $\begin{array}{l}\text { Pneumoconiosis } \\
\text { (14 deaths) }\end{array}$ & $\begin{array}{l}1 \\
2\end{array}$ & $\begin{array}{l}\text { Profusion* } \\
1.50(0.0001) \\
\text { Profusion* } \\
1.54(0.0001)\end{array}$ & $\begin{array}{l}\text { Millworking } \\
3.08(0.052) \\
\text { Millworking } \\
3.25(0.044)\end{array}$ & & \\
\hline $\begin{array}{l}\text { Lung cancer } \ddagger \\
\text { (12 deaths) }\end{array}$ & $1 \& 2$ & $\begin{array}{l}\text { Years since started work } \dagger \\
3.05(0.025)\end{array}$ & $\begin{array}{l}\text { Age started work } \dagger \\
2.02(0.040)\end{array}$ & & \\
\hline
\end{tabular}

${ }^{*}$ Relative risk per minor ILO category.

† Relative risk per 10 years.

$¥$ Does not include mesothelioma.

$\S p$ values in parentheses of difference of relative risk from unity.

no appreciable differences in the findings for the two readers. A comparison of their classification of the radiographs taken within two years of the claim for compensation shows a high degree of concurrence (table 2) (Kendall's tau $\mathrm{B}=0.73, \mathrm{p}<0.001$ ).

The significant determinants of death from all causes in the 238 subjects with radiographs near the

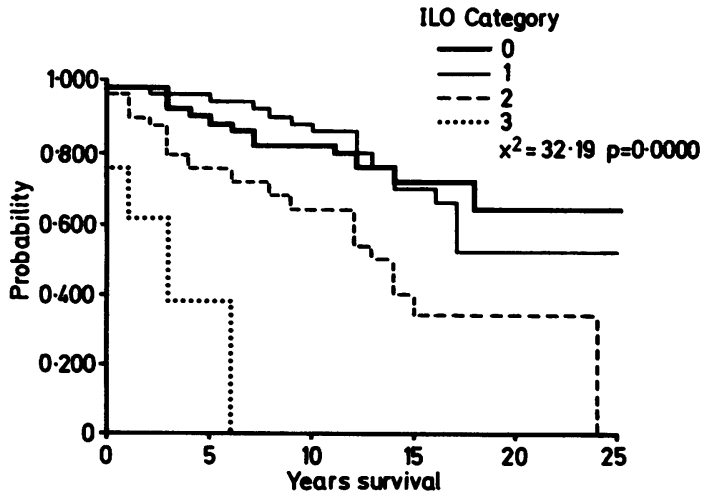

Fig 2 Survival from time of radiograph within two years of compensation in 238 subjects according to degree of radiographic abnormality. (Reader 2.) time of claim for compensation were found to be profusion of small opacities on the plain chest radiograph, age at starting work, time since starting work and working in the mill (table 3 ). The estimated total cumulative exposure was not a predictor of mortality. To investigate the possibility that underestimation of exposure in the mill was responsible for this negative finding, various values for mill

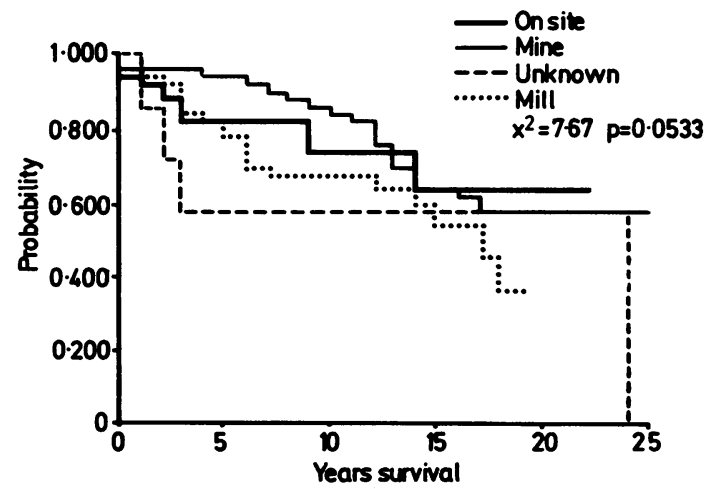

Fig 3 Survival from time of radiograph within two years of compensation in 238 subjects according to site of work. 
Table 4 Determinants of radiographic profusion in 238 subjects*

\begin{tabular}{|c|c|c|c|}
\hline Reader & $\begin{array}{l}\text { Partial regression } \\
\text { coefficient: } b\end{array}$ & Standard error of $b$ & Probability \\
\hline 1 & $\begin{array}{lr}\text { (Log) exposure } & 0.346 \\
\text { Time since starting work } & 0.077 \\
\text { Age at starting work } & 0.049 \\
\text { Constant } & -1.702 \\
\text { Multiple correlation coefficient: }=\mathbf{R}^{2}=10 \cdot 1 \%\end{array}$ & $\begin{array}{l}0 \cdot 095 \\
0.021 \\
0 \cdot 018 \\
0 \cdot 894\end{array}$ & $\begin{array}{l}0.0003 \\
0.0003 \\
0.006\end{array}$ \\
\hline 2 & $\begin{array}{lr}\text { (Log) exposure } & 0 \cdot 388 \\
\text { Time since starting work } & 0 \cdot 078 \\
\text { Age at starting work } & 0.046 \\
\text { Constant } & -1 \cdot 473 \\
\text { Multiple correlation coefficient: } \mathbf{R}^{2}=10.4 \%\end{array}$ & $\begin{array}{l}0.098 \\
0.021 \\
0.018 \\
0.923\end{array}$ & $\begin{array}{l}0.0001 \\
0.0002 \\
0.011\end{array}$ \\
\hline
\end{tabular}

* Multiple linear least squares regression. Values are for last step.

Variables in order of stepwise inclusion.

Profusion measured in minor categories of ILO classification.

Time and age measured in years.

exposure were tried in the equation until total exposure became a significant predictor of mortality and replaced mill working in the equation. This occurred only when the estimated mill exposure was increased by a factor of 50 (corresponding to an absolute fibre count of 5000 fibre/cc).

The median survival from the time of compensation claim for subjects with ILO category 1 pneumoconiosis was 17 years. For subjects with ILO category 2 pneumoconiosis median survival was 12 years and for subjects with category 3 disease only three years (fig 2). The median survival for mill workers was 17 years from the time of applying for compensation, whereas only $40 \%$ of mine workers who had applied for compensation had died before 31 December 1982 (fig 3).

When the 14 deaths from pneumoconiosis were considered separately, profusion and having worked in the mill remained positive predictors of death (table 3).

For the 12 subjects who died from lung cancer, age at starting work and time since starting work remained significant positive risk factors for death.
Because profusion of radiographic opacities was found to be a significant determinant of death, whereas estimated total exposure was not, the determinants of profusion were investigated. These were found to be (log) total exposure, age at starting work, and time since starting work (table 4).

In the 168 subjects who had completed full compensation procedures and who had been awarded compensation for disability by the pneumoconiosis medical board the percentage disability awarded was a positive predictor of death from all causes (table 5). In addition it was a significant predictor of death from pneumoconiosis and the most important predictor of death from lung cancer. The median survival time from compensation claim has not yet been reached for subjects awarded less than $25 \%$ disability (fig 4). For subjects with $26-50 \%$ disability the median survival was 24 years, for $51-75 \%$ disability 14 years, and for 76-100\% disability 12 years. The percentage disability awarded by the medical panel was itself predicted by the total exposure to asbestos $(p<0.0001)$ and the age at starting work $(p=0.045)$ (table 6$)$.

able 5 Predictors of cause of death in 168 subjects assessed for disability (proportional hazards regression analysis. ( $p$ values in zrentheses for difference of relative risk from unity)

\begin{tabular}{|c|c|c|c|c|c|c|}
\hline & Reader & Relative risks (p) & & & & \\
\hline $\begin{array}{l}\text { 1l causes } \\
\text { ( } 52 \text { deaths) }\end{array}$ & $\begin{array}{l}1 \\
2\end{array}$ & $\begin{array}{l}\text { Profusion }{ }^{*} \\
1.26(0.0001) \S \\
\text { Profusion }{ }^{*} \\
1.26(0.0007)\end{array}$ & $\begin{array}{l}\text { Years since starting work } \dagger \\
2.50(0.0005) \\
\text { Years since starting work } \dagger \\
2.53(0.0005)\end{array}$ & $\begin{array}{l}\text { \%Disability } \ddagger \\
1 \cdot 17(0.013) \\
\% \text { Disability } \ddagger \\
1 \cdot 21(0.0027)\end{array}$ & $\begin{array}{l}\text { Millworking } \\
1.79(0.047) \\
\text { Millworking } \\
1.60(0.109)\end{array}$ & $\begin{array}{l}\text { Age starting work } \dagger \\
1.38(0.072) \\
\text { Age starting work } \dagger \\
1.34(0.105)\end{array}$ \\
\hline $\begin{array}{l}\text { geumoconiosis } \\
\text { (14 deaths) }\end{array}$ & $\begin{array}{l}1 \\
2\end{array}$ & $\begin{array}{l}\text { Profusion* } \\
1.43(0.0002) \\
\text { Profusion* } \\
1.39(0.003)\end{array}$ & $\begin{array}{l}\text { \%Disability } \ddagger \\
1.33(0.006) \\
\% \text { Disability } \ddagger \\
1.33(0.008)\end{array}$ & $\begin{array}{l}\text { Millworking } \\
3.59(0.031) \\
\text { Millworking } \\
2.92(0.07)\end{array}$ & & \\
\hline $\begin{array}{l}\text { ung cancer\& } \\
\text { (10 deaths) }\end{array}$ & $1 \& 2$ & $\begin{array}{c}\text { \%Disability } \ddagger \\
1.44(0.009)\end{array}$ & $\begin{array}{l}\text { Years since starting work } \dagger \\
4.84(0.009)\end{array}$ & & & \\
\hline
\end{tabular}

Relative risk per minor ILO category.

Relative risk per 10 years.

Relative risk per $10 \%$ disability.

Does not include mesotheliomas. 


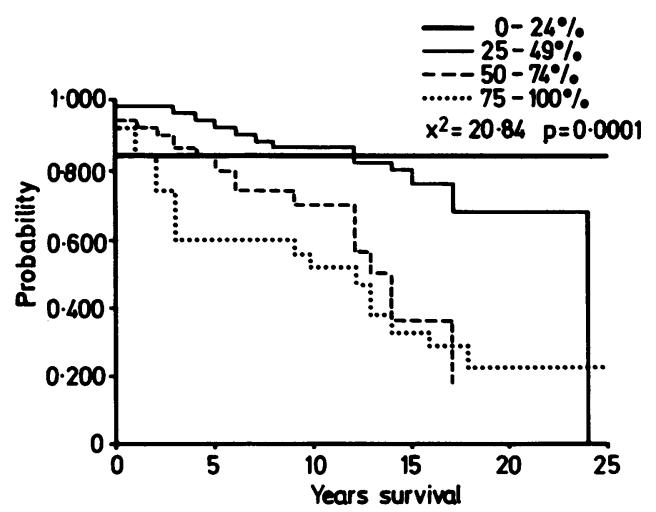

Fig 4 Survival from time of radiograph within two years of compensation in 168 subjects according to percentage disability compensation awarded.

\section{Discussion}

The results of this study of subjects exposed to crocidolite are in agreement with other studies of populations exposed to asbestos in showing increased mortality from pneumoconiosis, carcinoma of the lung, and malignant mesothelioma. Increased mortality from bronchitis and emphysema was also observed. This may be due to unrecognised pneumoconiosis and misclassification of the cause of death, or to a high proportion of cigarette smokers in this population. Symptoms of bronchitis have been found in subjects with asbestosis who do not smoke, ${ }^{7}$ however, and asbestos may cause airflow limitation by peribronchial fibrosis. ${ }^{22-25}$ The morbidity ratio for bronchitis and emphysema may thus reflect a true excess of asbestos related airways disease in these subjects. Although an excess of gastrointestinal cancers has been reported in heavily exposed asbestos workers, ${ }^{27}$ there was no significant increase in death rates for non-respiratory cancers in the men in this study or in the cohort composed of the total workforce. ${ }^{1}$ The excess deaths from tuber-

Table 6 Predictors of percent disability in 168 subjects*

\begin{tabular}{lccc}
\hline Variable & $\begin{array}{l}\text { Partial } \\
\text { regression } \\
\text { coefficient: } b\end{array}$ & $\begin{array}{l}\text { Standard } \\
\text { error }(b)\end{array}$ & Probability \\
\hline $\begin{array}{l}\text { (Log) cumulative } \\
\text { exposure }\end{array}$ & $5 \cdot 38$ & $1 \cdot 27$ & $<0.0001$ \\
$\begin{array}{l}\text { Age first started } \\
\text { work (years) }\end{array}$ & $\begin{array}{c}0 \cdot 441 \\
13 \cdot 34\end{array}$ & $\begin{array}{l}0 \cdot 215 \\
9.76\end{array}$ & -0.042 \\
$\begin{array}{l}\text { Constant } \\
\text { Multiple correlation coefficient: } \mathrm{R}^{2}=10.6 \%\end{array}$ & - \\
\hline
\end{tabular}

${ }^{*}$ Multiple linear least-square regression. Values are for last step. Variables in order of stepwise inclusion. culosis in this study may be attributed to the large numbers of European immigrants in the Wittenoom population and possibly to the co-existence of silicosis since the crocidolite existed in siliceous parent rock.

Examination of the determinants of survival showed that working in the mill was associated with excess mortality from all causes and from pneumoconiosis (but not from lung cancer). This effect was independent of the estimated total exposure to asbestos based on fibre counts performed in 1966. Working in the mill may have been disproportionately hazardous because the concentrations of dust in the mill were actually higher than the 1966 measurements indicate, or because of differing fibre dimensions between mill and mine. The 1966 exposure concentrations may well have been conservative estimates of usual concentrations in the two mills because historical information suggests that the old mill in Wittenoom Gorge which operated before 1957 was much dustier than the new mill in Colonial Gorge, and because we have no means of estimating the effects of the long hours of overtime that were common for the workforce. ${ }^{8}$ Exposure in the mill, however, is unlikely to have been underestimated by the factor of 50 necessary to make total exposure a significant predictor of mortality in place of a history of working in the mill. In addition, the risk of carcinoma of the lung in asbestos workers has been shown to be related to the amount of exposure..$^{1-3}$ Therefore a simple underestimation of fibre counts in the mill would have been expected to cause mill working to predict mortality from carcinoma of the lung as well as pneumoconiosis. Elsewhere occupational exposure to refined asbestos fibre has been shown to be more dangerous than exposure to unrefined asbestos, ${ }^{26}$ perhaps due to the effect of processing on fibre dimensions $^{27}$ and airborne dispersion. This effect may have been operating at Wittenoom. It could also have been due to different smoking habits in mill and mine, although available information does not suggest this.

The lack of an effect of degree of asbestos exposure on mortality from carcinoma of the lung in these subjects is unexplained. It may be due to subject selection and the limited range of exposure of all subjects in this cohort, the small numbers of cases of carcinoma, or the inability to include data on tobacco use in the statistical model. Additionally, $\varnothing$ the assumption of independence of competing causes of death implicit in the analysis, whereby? people dying from other causes than the one for 0 which risks are being estimated are included in the alive/censored group is probably invalid because of the common exposure agent and the common site of 
disease. Therefore the three different analyses must be viewed as a whole and any interpretations of significant effects regarded as comparative rather than absolute considering the proportionately large numbers of deaths from lung cancer and asbestosis. It should be noted that positive predictive effects of age at starting work and time since starting work on risk of lung cancer imply a positive effect of age at radiography on risk of death from lung cancer. Indeed age at radiography could replace these other two variables in the model.

The study shows that death from pneumoconiosis may be predicted by the degree of profusion of small opacities on the plain chest radiograph independently of age. Survival was greatly shortened once category 3 had been reached. Previous investigations have shown only that the presence or absence of pneumoconiosis on the radiographs of subjects who are still at work predicts mortality, ${ }^{4-728}$ but the duration of survival has not previously been related to the radiographic severity of pneumoconiosis.

While estimates of total exposure per se were not predictive of mortality from any cause, the radiographic profusion of small opacities was predictive. Probably the effect of exposure on mortality has been mediated through the individual tissue response to inhaled asbestos, and the radiographic profusion score reflects the degree of response to some extent. Investigation of the determinants of profusion showed exposure to be the single most important predictor of eventual radiographic outcome even in this group, most of whom had relatively high exposure in comparison with the total workforce. Profusion was also seen to be dependent on the time since starting work (which is consistent with the progressive nature of asbestosis in these subjects) and on increasing age at starting work (which has been suggested in earlier investigations) ${ }^{29}$ It could be, however, that the latter merely reflects increased likelihood of other exposures before starting work at Wittenoom or that the two variables together are simply reflecting an effect of age on the radiographic appearances associated with asbestos exposure.

When the percentage disability determined by the medical panel was included in the estimation of possible determinants of mortality, it was a significant predictor of death from all causes in addition to death from pneumoconiosis and from lung cancer. It was the single best predictor of death from lung cancer. These findings probably relate to the accurate recognition of sick subjects by the medical panel. The percentage disability awarded was itself a function of total exposure to asbestos, and the age at first starting work. It is uncertain how these variables were being recognised by the examining physi- cians. They are likely to have taken radiographic profusion into account which was itself strongly related to exposure, or they may have been more sympathetic towards individuals who had a history of higher exposure.

This study has shown excessive mortality of claimants for pneumoconiosis compensation among Wittenoom crocidolite workers and that the survival of these subjects is significantly related to the radiographic category of asbestosis and the percentage disability for which compensation payments were made. An excess of mortality has been shown to be associated with work in the mill at Wittenoom, which cannot be satisfactorily accounted for by estimates of the total exposure of the subjects to asbestos.

The help of Dr J Cassidy and staff of the Perth Chest Clinic, Miss E Bingle, Mrs J Eccles, and Mrs B Blunsdon is gratefully acknowledged.

\section{References}

' Hobbs MST, Woodward SD, Murphy B, Musk AW, Elder JE. The incidence of pneumoconiosis, mesothelioma and other respiratory cancer in men engaged in mining and milling crocidolite in Western Australia. In: Wagner JC, ed. Biological effects of mineral fibres. Lyon: International Agency for Research on Cancer, 1980:615-25. (IARC scientific publications No 30.)

${ }^{2}$ Enterline P, DeCoufle P, Henderson V. Respiratory cancer in relation to occupational exposures among retired asbestos workers. Br J Ind Med 1973;30: 162-6.

${ }^{3}$ McDonald JC, Liddell FDK, Gibbs GW, Eyssen GE, McDonald AD. Dust exposure and mortality in chrysotile mining, 191075. Br J Ind Med 1980;37:11-24.

${ }^{4}$ Berry G. Mortality of workers certified by pneumoconiosis medical panels as having asbestosis. $\mathrm{Br} J$ Ind Med 1981;38:130-7.

${ }^{5}$ Finkelstein M, Kusiak R, Surany G. Mortality among workers receiving compensation for asbestosis in Ontario. Can Med Assoc J 1981;125:259-62.

- Liddell FDK, McDonald JC. Radiological findings as predictors of mortality in Quebec asbestos workers. Br J Ind Med 1980;37:257-67.

${ }^{7}$ Husskonen MS. Clinical features, mortality and survival of patients with asbestosis. Scand J Work Environ Health $1978 ; 4: 265-74$

${ }^{8}$ Layman L. Work and workers' responses at Wittenoom 1943 66. Community Health Stud 1983;7:1-18.

` Weill H, Rossiter CE, Waggenspack C, Jones RN, Ziskind MN. Differences in lung effects resulting from chrysotile and crocidolite exposure. In: Walton WH, ed. Inhaled particles $I V$. Oxford: Pergammon Press 1978:789-98.

${ }^{10}$ Sulotto F, Romano C, Berra A, Arossa W, Spinaci S. Radiographic and functional changes following exposure to different types of asbestos. In: Wagner JC, ed. Biological effects of mineral fibres. Lyon: International Agency for Research on Cancer, 1980:565-8. (IARC scientific publications No 30.)

" Jones JSP, Pooley FD, Clarke NJ, et al. The pathology and mineral content of lungs in cases of mesothelioma in the United Kingdom in 1976. In: Wagner JC, ed. Biological effects of mineral fibres. Lyon: International Agency for Research on Cancer, 1980:187-99. (IARC scientific publications No 30.) 
${ }^{12}$ International Labour Office. Guidelines for the use of ILO international classification of radiographs on pneumoconiosis. Geneva: ILO, 1980. (Occupational safety and health series, No 22.)

${ }^{13}$ Major G. Asbestos dust exposure. In: Major G, ed. Proceedings first Australian pneumoconiosis conference Sydney, 1968. Sydney: Joint Coal Board, 1968:467-74.

${ }^{14}$ Case IM, Lea AJ. Mustard gas poisoning, chronic bronchitis, and lung cancer. Br J Prev Soc Med 1955;9:62-72.

is Peto J. Man years computer programme. Oxford: ICRF Cancer Unit, 1980.

${ }^{16}$ Kaplan EL, Meier P. Non-parametric estimation from incomplete observations. Journal of the American Statistical Association 1958;53:457-81.

17 Buckley JD. Survival programme. Parkville, Australia: Clinical Research Unit, Walter and Eliza Hall Institute of Medical Research, 1979.

${ }^{18}$ Kalbfleisch JD, Prentice RL. Statistical analysis of failure time data. New York: Wiley and Sons, 1980.

1" Thomas DC. Programme "RISK." Montreal: Department of Epidemiology and Health, McGill University, 1980.

${ }^{20}$ Snedecor GW, Cochrane WG. Statistical methods. Iowa: Iowa State University Press, 1972.

${ }^{21}$ Nie NH, Hull GH, Jenkins JG, Steinbrenner K, Bent D. Statistical package for the social sciences. New York: McGraw Hill, 1975.
${ }^{22}$ Muldoon BC, Turner-Warwick M. Lung function studies in asbestos workers. Br J Dis Chest 1972;66:121-32.

${ }^{23}$ Fournier-Massey G, Becklake MR. Pulmonary function profiles in Quebec asbestos workers. Bull Physiopath Respir 1975; 11:429-45.

${ }^{24}$ Jodoin G, Gibbs GW, Macklem PT, McDonald JC, Becklake MR. Early effects of asbestos exposure on lung function. Am Rev Respir Dis 1971;104:525-35.

${ }^{25}$ Heitt DM. Experimental asbestosis: an investigation of functional and pathological disturbances. II. Results for chrysotile and amosite exposures. $\mathrm{Br} J$ Ind Med 1978;35:135-45.

${ }^{26}$ McDonald AD. Malignant mesothelioma in Quebec. In: Wagner JC, ed. Biological effects of mineral fibres. Lyon: International Agency for Research on Cancer, 1980:673-80. (IARC scientific publication No 30.)

${ }^{27}$ Stanton MF, Wrench C. Mechanisms of mesothelioma induction with asbestos and fibrous glass. J Natl Cancer Inst 1972; 48:797-821.

${ }^{28}$ Liddell FDK. Validation of the UICC/Cincinatti classification of radiographs in terms of prediction of mortality of asbestos workers. In: Wagner JC, ed. Biological effects of mineral fibres. Lyon: International Agency for Research on Cancer, 1980:667-71. (IARC scientific publications No 30.)

${ }^{29}$ Viallat JR, Boutin C, Pietri JF, Fondarai J. Late progression of radiographic changes in Canari chrysotile mine and mill exworkers. Arch Environ Health 1983;38:54-8.

\section{Correspondence and editorials}

The British Journal of Industrial Medicine welcomes correspondence relating to any of the material appearing in the journal. Results from preliminary or small scale studies may also be published in the correspondence column if this seems appropriate. Letters should be not more than $\mathbf{5 0 0}$ words in length and contain a minimum of references. Tables and figures should be kept to an absolute minimum. Letters are accepted on the understanding that they may be subject to editorial revision and shortening.

The journal now also publishes editorials which are normally specially commissioned. The Editor welcomes suggestions regarding suitable topics; those wishing to submit an editorial, however, should do so only after discussion with the Editor. 